\title{
SEDAÇÃO NA ODONTOLOGIA BRASILEIRA: PASSADO, PRESENTE E FUTURO ANÁLISE HISTÓRICO-NORMATIVA E PERSPECTIVAS FUTURAS
}

\author{
SEDATION IN BRAZILIAN DENTISTRY: PAST, PRESENT, FUTURE. \\ HISTORICAL-NORMATIVE ANALYSIS AND FUTURE PERSPECTIVES
}

\author{
André Takahashi', Vitoldo Antônio Kozlowski Junior', Márcia Thais Pochapski', \\ Hedelson Odenir Iecher Borges ${ }^{2}$, Luciana Dorochenko Martins', Marcelo Carlos \\ Bortoluzzi $^{1}$ \\ ${ }^{1}$ Universidade Estadual de Ponta Grossa, Departamento de Odontologia, Ponta Grossa, \\ Paraná, Brasil. \\ ${ }^{2}$ Universidade Estadual de Londrina, Departamento de Odontologia, Londrina, Paraná, \\ Brasil \\ *Autor correspondente: André Takahashi, Departamento de Odontologia. Av. General Carlos \\ Cavalcanti, 4748 - Ponta Grossa - PR. CEP 84030-900. Telefone institucional: (42) 3220- \\ 3000 email: andrehtakahashi@gmail.com
}

\section{RESUMO}

Existem diversas técnicas de sedação que Cirurgiões-Dentistas podem dispor para o manejo eficiente da dor e do sofrimento durante o tratamento dentário.

Objetivo: O objetivo deste trabalho foi identificar as tendências para o futuro da sedação em Odontologia dentro de um contexto histórico normativo.

Método: Este trabalho fez um breve levantamento histórico da descoberta da anestesia, da evolução da Odontologia como profissão, e analisou as normas atuais que regulamentam a anestesia e a sedação na Odontologia Brasileira, com o propósito de detectar tendências para um futuro próximo e, assim, orientar esforços para satisfação das necessidades presentes.

Resultados: A Odontologia tornou-se profissão independente e autônoma, com suas especificidades técnico-científicas e normativas. As técnicas de sedação e anestesia sempre foram objeto de disputas entre classes profissionais. Atualmente, o direito de utilizar analgesia/sedação teve como marco regulatório a Resolução CFO 51/2004.

Conclusão: Conclui-se que há a necessidade de preparar o futuro da Odontologia e os Cirurgiões-dentistas para a utilização das diversas técnicas de sedação dos pacientes.

Palavras chave: História da Odontologia; Sedação; Regulamentação da Odontologia.

\begin{abstract}
There are several sedation techniques that Dental Surgeons can provide for the efficient management of pain and suffering during dental treatment.

Objective: The objective of this study was to identify trends for the future of sedation in dentistry within a normative historical context.

Method: This work made a brief historical survey of the discovery of anesthesia, of the evolution of Dentistry as a profession, and analyzed the current norms that regulate anesthesia and sedation in Brazilian Dentistry, with the purpose of detecting tendencies for the near future and thus guide efforts to meet present needs.

Results: Dentistry became an independent and autonomous profession, with its technicalscientific and normative specificities. The techniques of sedation and anesthesia have always been the object of disputes between professional classes. Currently, the right to use analgesia / sedation has as its regulatory framework Resolution CFO 51/2004.

Conclusion: It is concluded that there is a need to prepare the future of dentistry and dentists to use the various sedation techniques of patients.
\end{abstract}

Key words: History of Dentistry; Sedation; Law of Dentistry. 


\section{INTRODUÇÃO}

A descoberta da anestesia revolucionou as especialidades cirúrgicas. Intervenções cirúrgicas que anteriormente eram realizadas às pressas, sob a dor $\mathrm{e}$ o sofrimento, passaram a ser realizadas com cuidado e precisão técnica, sob analgesia e conforto para o paciente. A dor e o sofrimento não eram mais limites para qualquer procedimento cirúrgico.

A dor pode ser definida como uma experiência subjetiva que pode estar associada a dano real ou potencial nos tecidos, podendo ser descrita tanto em termos desses danos quanto por ambas as características. Independentemente da aceitação dessa definição, a dor é considerada como uma experiência genuinamente subjetiva e pessoal. A percepção de dor é caracterizada como uma experiência multidimensional, diversificando-se na qualidade e na intensidade sensorial, sendo afetada por variáveis afetivomotivacionais (SOUZA 2002).

Durante a maior parte da história humana, a dor não era sintoma de doenças ou a reação do corpo ao mau funcionamento de um órgão. Era vista como punição divina ou forma de purificar a alma. Só a partir da II Guerra Mundial começamos a enxergar a dor da maneira contemporânea. A mudança mais significativa é que passamos a lidar com a dor não com rezas ou orações, mas com analgésicos. Suportar de modo impassível as dores excruciantes foi virtude valorizada até os anos 1970, quando a indústria farmacêutica desenvolveu analgésicos e anestésicos eficazes. A valorização da dor como uma virtude é uma herança de épocas que a possibilidade médica de erradicar dores agudas era limitada. A partir do momento em que o alívio verdadeiro surgiu, a tolerância ao sofrimento deixou de ser uma atitude louvável e se tornou perversa. Despida do misticismo religioso, a dor se tornou um mal em si mesma. Foi quando ela passou a ser uma inimiga a ser combatida e vencida (BURKE, 2014).

Diversas técnicas para o controle da dor e do sofrimento foram desenvolvidas, baseadas na boa comunicação, fornecimento de informações, efetiva anestesia loco-regional, hipnose e medicamentos sedativos (FACCO; ZANETTE, 2017).

Sedação é um estado de depressão do nível de consciência induzida por drogas, em diferentes níveis de intensidade (MALAMED, 1986). De acordo com doses administradas e respostas individuais do paciente, o resultado varia desde a consciência com leve tranquilidade até a inconsciência. A sedação pode ser provocada por diversos medicamentos e, além do óxido nitroso, os mais utilizados são: barbitúricos (notadamente o tiopental sódico), benzodiazepínicos (incluindo o midazolam, o diazepam e o lorazepam, não disponível no Brasil para infusão parenteral), derivados fenólicos (propofol), neurolépticos (limitados em sedação exclusivamente ao haloperidol), opióides (incluindo a morfina e o fentanil e seus derivados) e agentes inalatórios (particularmente o isoflurano) (BENSENHOR; CICARELLI, 2003).

Lino et al. (2017) estudaram 16.436 prescrições de ansiolíticos, sedativos e hipnóticos feitas por dentistas no Brasil e concluíram que os benzodiazepínicos e derivados foram os medicamentos mais frequentemente prescritos. Havia uma baixa taxa de receita dentária para ansiolíticos, sedativos e hipnóticos, embora as doses excessivas fossem concentradas na mesma receita. Essas conclusões mostram que a taxa per capita (100.000 habitantes) para prescrição dessas drogas é muito baixa quando comparada à alta prevalência de ansiedade dental ou fobia dentária entre adultos, adolescentes e crianças.

O medo do tratamento dental na população é uma medida indireta da falha na abordagem terapêutica para a redução da dor e da ansiedade, que inviabiliza o tratamento odontológico para parte da população (DIONNE, 1998).

\section{PROPOSIÇÃO}

O objetivo deste trabalho é responder à questão: Dentro de um panorama histórico normativo, quais as tendências para o futuro da sedação em Odontologia?

\section{METODOLOGIA}

Este trabalho fez um breve levantamento histórico da descoberta da anestesia, da evolução da Odontologia como profissão, e analisou as normas atuais que regulamentam a anestesia e a sedação na Odontologia. 
ANÁLISE HISTÓRICO-NORMATIVA E PERSPECTIVAS FUTURAS

\section{RESULTADOS}

\section{O passado}

\section{Breve análise histórica do contexto do descobrimento da anestesia}

A realização de extrações dentárias sem sofrimento foi parâmetro na descoberta da anestesia geral. O cirurgião-dentista Horace Wells, vendo uma apresentação em que os participantes eram entretidos com óxido nitroso, notou que uma pessoa, Samuel Cooley, feriu a própria perna e não se queixou de dor, ele imediatamente pensou em usar o gás para realizar extrações dentárias. No dia seguinte, 11 de dezembro de 1844, inalou o gás e seu colega, John Riggs, extraiulhe o dente (ORR II, 2013). O médico Roberto Jorge Haddock Lobo foi um dos pioneiros a utilizar a anestesia no Brasil, no dia 20 de maio de 1847, no Hospital Militar do Rio de Janeiro. Ele anestesiou com éter Francisco D' Assis Paes Leme, aluno do terceiro de medicina, para extrair um dente molar que lhe causava uma fístula facial (SILVA, 1920).

A anestesia local foi descoberta depois, em 1884, pelo Oftalmologista Karl Köller, que utilizou cocaína para realizar anestesia tópica para cirurgias oftalmológicas (LÓPEZ-VALVERDE et al., 2011). William Stewart Halsted, "pai da cirurgia moderna", e Richard John Hall, cirurgiões do Hospital John Hopkins, utilizaram a descoberta de Köller para o bloqueio regional de nervos. Em 6 de dezembro de 1884, Hall publica o primeiro bloqueio bem-sucedido no contexto da Odontologia: dr. Charles A. Nash, de Nova York, realizou o bloqueio do plexo infraorbital com $0,5 \mathrm{ml}$ (8 minims) de hidrocloreto de cocaína $4 \%$, para obturar um incisivo superior, considerando que o dr. Halsted bloqueou o nervo alveolar inferior de um estudante de medicina usando 9 minims da mesma solução (CALATAYUD; GONZALEZ, 2003). No Brasil, o médico Alphonse Marie Edmond Pavie, amigo de Victor Pauchet, foi o primeiro a usar cocaína injetável (GUSMÃO, 2002).

Historicamente, dentistas e médicos sempre procuraram meios para minimizar o sofrimento dos pacientes submetidos a cirurgias bucais, e a utilização das técnicas de anestesia e sedação sempre foram comuns a ambas profissões.

\section{Breve análise histórica do surgimento da odontologia}

A Odontologia teve como marco inicial a publicação da obra do médico francês, Pierre Fauchard, intitulada Le Chirurgien Dentiste, em 1728 (MARTINS, 2017). A prática de Fauchard não se restringia à remoção dos dentes, mas restaurava os dentes cariados, retirava o tártaro dos dentes e os tumores benignos da gengiva. A reabilitação com próteses dentárias (ROUSSEAU, 2006) era uma de suas especialidades e ele foi o primeiro a considerar Odontologia como arte e ciência. Em seu trabalho, destacou a relação das doenças sistêmicas com as doenças bucais (LYNCH, 2006). Fauchard também tratava pacientes com fissuras palatinas, naquela época, resultantes de sequelas da sífilis ou causada por traumas, reabilitando-os com "obturadores". Os praticantes da Odontologia, nesse tempo, poderiam ser descritos em duas categorias: os que não tinham treinamento, os "tiradentes", que frequentavam as feiras das aldeias e atendiam os pobres usando poções mágicas e feitiços para tratar doenças dentárias e dores de dente; e os que tinham alguma forma de treinamento em cirurgia, que atendiam os membros das classes mais alta que podiam pagar pelas habilidades de praticantes mais respeitáveis (LYNCH, 2005).

No Brasil Colonial, não existia uma categoria profissional para realizar tratamento dos dentes, assim como ocorria na metrópole portuguesa e nos demais países da Europa (PEREIRA, 2012). A falta de profissionais habilitados e as inúmeras dificuldades de acesso ao conhecimento técnico-científico fizeram com que a Odontologia, nesse período, fosse exercida por leigos, principalmente barbeiros (FIGUEIREDO, 2017). Não existia o recurso da anestesia, sendo assim, era muito importante a rapidez do procedimento para que a exposição a dor fosse o mais breve possível (PEREIRA, 2012).

A instalação da Família Real Portuguesa no Brasil, devido às Guerras Napoleônicas, proporcionou o desenvolvimento da colônia e a fundação do curso de Medicina. O Carta Régia de 18 de fevereiro de 1808 criou a escola de Cirurgia do Hospital Militar da Bahia, e em 5 de novembro do mesmo ano, é instituída no Hospital Militar do Rio de Janeiro, uma Escola Anatômica, Cirúrgica e Médica (FÁVERO, 1999). O Decreto 9.311 de 25 outubro de 1884 cria o novo 
estatuto das faculdades de medicina e individualiza o curso de Odontologia.

Art. $1^{\circ}$ Cada uma das Faculdades de Medicina do Imperio se designará pelo nome da cidade em que tiver assento; será regida por um Director e pela Congregação dos lentes, e se comporá de um curso de sciencias medicas e cirurgicas, e de tres cursos annexos: o de pharmacia, o de obstetricia e gynecologia e o de odontologia. [sic]

O curso de Odontologia estava oficialmente estabelecido nas faculdades de medicina do Rio de Janeiro e da Bahia. Em 1893, os estudantes do curso começaram a receber o diploma de cirurgião-dentista e, em 1919, o curso foi transferido para da Faculdade de Odontologia no Rio de Janeiro, que em 1933 foi incorporada à Universidade do Rio de Janeiro, fundada em 1920. Em 28 de outubro de 1934, o novo prédio da Faculdade de Odontologia do Rio de Janeiro foi inaugurado na Praia Vermelha. A Universidade do Brasil e a Faculdade de Odontologia tornou-se conhecida como Faculdade de Odontologia Nacional, em 1937 (MAGALHÃES, 1996).

As mudanças sociais e a transformação nos padrões de consumo do açúcar determinaram a disseminação da doença cárie dentária na sociedade e a expansão do mercado de serviços odontológicos. A consequente proliferação de grupos distintos de praticantes, qualificados e desqualificados na arte dental, competindo pelo mercado de serviços odontológicos, evidenciam as disputas travadas em torno do estabelecimento de uma jurisdição e monopólio sobre esse campo de trabalho e fazem parte da emergência da odontologia como profissão independente (CARVALHO, 2006).

A separação entre práticas dentárias e médicas foi condição de possibilidade para o nascimento da profissão odontológica, e esse acontecimento não apenas representou, para a odontologia, prescindir dos conhecimentos e procedimentos intrínsecos à clínica médica, ele também direcionou seu contexto científico de criação. A instituição do embasamento científico da profissão foi produzida, em grande parte, a partir dessa autonomia. $\mathrm{O}$ ensino da odontologia tem origens diversas: as práticas dentárias dos barbeiros, cirurgiões e médicos; necessidade de organizar e articular sistemas de profissionalização, regulação e ensino das práticas de cura; mudanças nos padrões de compreensão das doenças bucais e das respostas técnico-científicas que se constituíram para elas. Ao modo de um tabuleiro de xadrez, políticas e estratégias foram se relacionando, estabelecendo e formando o sistema de ensino da odontologia consolidado na atualidade. Tais estratégias definiram e moldaram a subjetividade do cirurgiãodentista contemporâneo e também a clínica por ele desempenhada (WARMLING, 2012).

\section{ANÁLISE NORMATIVA}

\section{O presente}

Há uma hierarquia entre as normas jurídicas. As normas jurídicas não são todas iguais, elas se dividem em categorias hierarquizadas, em que uma lei suplanta a outra de categoria inferior. No Brasil, esse sistema normativo tem, em ordem decrescente de hierarquia, a seguinte conformação: Constituição Federal, Emenda à Constituição, Leis Complementares, Leis Ordinárias, Leis Delegadas, Medidas Provisórias, Decretos Legislativos, Resoluções e Portarias, Contratos e Sentenças.

$\mathrm{Na}$ Constituição Federal, encontramos o direito fundamental de liberdade de profissão previsto no art. $5^{\circ}$, XIII:

XIII - é livre o exercício de qualquer trabalho, ofício ou profissão, atendidas as qualificações profissionais que a lei estabelecer; [...]

A Lei Federal $n^{\circ} 5081 / 1966$, que regula o exercício da Odontologia, enumera as competências do cirurgião-dentista, delimitando e protegendo sua área de atuação como profissão autônoma, e lhe garante o direito para aplicar anestesia local e troncular e empregar analgesia e a hipnose, desde que comprovadamente habilitado e quando se constituírem meios eficazes para o tratamento.

Art. $6^{\circ}$ Compete ao cirurgião-dentista:

$\mathrm{V}$ - aplicar anestesia local e truncular [sic];

VI - empregar a analgesia e a hipnose, desde que comprovadamente habilitado, quando constituírem meios eficazes para o tratamento; $[. .$.

A Resolução CFO 63/2005 - Consolidação das normas para procedimentos nos Conselhos de Odontologia, especifica as Práticas privativas do cirurgião-dentista

Art. $4 \mathrm{O}$ exercício das atividades profissionais privativas do cirurgião-dentista só é permitido com a observância do disposto nas Leis 4.324, de 14/04/64 e 5.081, de 24/08/66, no Decreto n.o 68.704, de 03/06/71; 


\section{ANÁLISE HISTÓRICO-NORMATIVA E PERSPECTIVAS FUTURAS}

e, demais normas expedidas pelo Conselho Federal de Odontologia.

$\S$ 1o. Compete ao cirurgião-dentista:

V - aplicar anestesia local e troncular;

VI - empregar a analgesia e a hipnose, desde que comprovadamente habilitado, quando constituírem meios eficazes para o tratamento;

$\S$ 2o. O cirurgião-dentista poderá operar pacientes submetidos a qualquer um dos meios de anestesia geral, desde que sejam atendidas as exigências cautelares recomendadas para o seu emprego.

§ 3o. O cirurgião-dentista somente poderá executar trabalhos profissionais em pacientes sob anestesia geral quando a mesma for executada por profissional médico especialista e em ambiente hospitalar que disponha das indispensáveis condições comuns a ambientes cirúrgicos.

Art. 44. Os cirurgiões-dentistas somente poderão realizar cirurgias sob anestesia geral, em ambiente hospitalar, cujo diretor técnico seja médico, e que disponha das indispensáveis condições de segurança comuns a ambientes cirúrgicos, considerando-se prática atentatória à ética a solicitação e/ou a realização de anestesia geral em consultório de cirurgião-dentista, de médico ou em ambulatório."

Art. 45. Somente poderão ser realizadas, em consultórios ou ambulatórios, cirurgias passíveis de serem executadas sob anestesia local.

Oxido Nitroso Resolução CFO 51/04 - Baixa normas para habilitação do CD na aplicação da analgesia relativa ou sedação consciente, com óxido nitroso.

Art. $1^{\circ}$. Será considerado habilitado pelos Conselhos Federal e Regionais de Odontologia a aplicar analgesia relativa ou sedação consciente, o cirurgião-dentista que atender ao disposto nesta Resolução.

Art. $2^{\circ}$. O curso deverá ter sido autorizado pelo Conselho Federal de Odontologia, através de ato específico, ministrado por Instituição de Ensino Superior ou Entidade da Classe devidamente registrada na Autarquia.

$\S 1^{\circ}$. O pedido de autorização de funcionamento deverá ser requerido ao CFO, através do Conselho Regional da jurisdição, em formulário próprio.

$\S 2^{\circ}$. Exigir-se-á, para o curso, uma carga horária mínima de 96 (noventa e seis) horas/aluno.

$\S 3^{\circ}$. Do conteúdo programático deverão constar, obrigatoriamente, as seguintes matérias:

a) história do uso da sedação consciente com óxido nitroso:

a.1. a origem do uso do óxido nitroso.

a.2. o desenvolvimento da técnica de sedação.

a.3. a evolução dos equipamentos;

b) introdução à sedação: b.1. conceitos e definições.

b.2. classificação dos métodos de sedação.

b.3. sinais objetivos e subjetivos da sedação consciente com a mistura de oxigênio e óxido nitroso;

c) emergências médicas na clínica odontológica e treinamento em suporte básico de vida (teóricoprático);

d) dor e ansiedade em Odontologia:

d.1. conceitos de dor e ansiedade.

d.2. fobias;

e) anatomia e fisiologia dos sistemas nervoso central, respiratório e cardiovascular:

e.1. estruturas anatômicas envolvidas na respiração.

e.2. mecânica respiratória e composição dos gases respiratórios.

e.3. estágios da depressão do sistema nervoso central;

f) avaliação física e psicológica do paciente:

f.1. história médica (anamnese).

f.2. exame físico (sinais vitais, inspeção visual, funções motoras).

f.3. classificação do estado físico do paciente (ASA);

g) monitoramento durante a sedação:

g.1. monitoramento dos sinais vitais: pulso, pressão arterial, respiração.

g.2. monitoramento, através de equipamentos

(oximetria);

h) farmacologia do óxido nitroso:

h.1. preparação e propriedades químicas e físicas.

h.2. solubilidade e potência.

h.3. farmacocinética e farmacodinâmica.

h.4. ações farmacológicas no organismo.

h.5. contra-indicações;

i) a técnica de sedação consciente com a mistura de oxigênio e óxido nitroso:

i.1. visita prévia e instruções.

i.2. preparação do equipamento.

i.3. preparação do paciente.

i.4. administração dos gases e monitoramento.

i.5. liberação do paciente;

j) equipamento de dispensação da mistura de oxigênio e óxido nitroso:

j.1. tipos de máquinas de dispensação da mistura de oxigênio e óxido nitroso.

j.2. componentes das máquinas de dispensação.

j.3. cilindros de armazenagem dos gases (cilindro de óxido nitroso e cilindro de oxigênio).

j.4. componentes para a dispensação (mangueira, tubos e conexões).

j.5. máscaras e cânula nasal.

j.6. equipamentos para remoção ambiental do óxido nitroso (exaustão);

k) segurança no manuseio do equipamento e dos gases;

1) vantagens e desvantagens da técnica;

m) complicações da técnica;

n) abuso potencial, riscos ocupacionais e efeitos 
alucinatórios do óxido nitroso;

o) adequação do ambiente de trabalho;

p) normas legais, bioética e recomendações relacionadas com o uso da técnica de sedação consciente com a mistura de oxigênio e óxido nitroso;

q) prontuário para o registro dos dados da técnica de sedação consciente com a mistura de oxigênio e óxido nitroso.

$\S 4^{\circ}$. Ao final de cada curso deverá ser realizada uma avaliação teórico-prática.

No Estado do Paraná a Secretaria de Estado da Saúde no Paraná - SESA - através do Regulamento SESA 496/2005, regulamentou a Norma Técnica que estabelece condições para instalação e funcionamento de Estabelecimentos de Assistência Odontológica, e classificou os estabelecimentos Odontológicos com base na utilização do Raio - X.

9 - Os EAO classificam-se em: 9.1 - Consultório odontológico tipo I: é o EAO caracterizado por possuir somente um conjunto de equipamento odontológico, e que não faz uso de equipamento de raios- X odontológico (intrabucal). 9.2 - Consultório odontológico tipo II: é o EAO caracterizado por possuir somente um conjunto de equipamento odontológico, e que faz uso de equipamento de raios-X odontológico.

\section{DISCUSSÃO}

\section{O FUTURO}

Pela análise histórica do surgimento da Odontologia como profissão, inicialmente, no Brasil, desenvolveu-se como um campo de conhecimento vinculado à Medicina, a Estomatologia, entretanto, com a Reforma Saboya, a Odontologia tornou-se ramo de conhecimento e profissão independente e, atualmente, a Odontologia no Brasil organiza-se como uma profissão com autonomia técnico-cientifica, regida por práticas e normas específicas e próprias.

Pela análise histórica da analgesia, infere-se que essa matéria, de interesse comum dos pacientes e da sociedade em geral, tornou-se pela profissionalização e especialização, objeto de disputa entre as diversas classes profissionais. Os bastidores da aprovação da Resolução CFO 51/2004 nos dão a dimensão de como tais questões entre as classes profissionais afetam a prática clínica e a longa luta empreendida pela classe Odontológica para ver o reconhecimento à prática da sedação consciente (FERRARI et al., 2012).
No passado, o Decreto lei n ${ }^{\circ} 20.931 / 1932$ limitou a Odontologia aos anestésicos tópicos: “Art. $30 \mathrm{O}$ cirurgião-dentista somente poderá prescrever agentes anestésicos de uso tópico e medicamento de uso externo para os casos restritos de sua especialidade", inviabilizando, na prática, a realização das exodontias sem dor e sofrimento. Somente depois de 19 anos, a partir da Lei 1314/1951, o cirurgião-dentista teve o direito de prescrever e administrar anestesia local e troncular. Atualmente, a Lei 5081/1966, consagrou a utilização de anestesias loco-regionais e o uso da analgesia e hipnose. Dessa forma, a Resolução CFO 51/04 é um marco garantidor do direito de utilizar a sedação em odontologia. As perspectivas futuras são de consolidação dessa e de outras formas de sedação, tendências previsíveis que devem ser incorporadas e desde já preparadas pelas Faculdades de Odontologia, em seus currículos, e Conselhos Regionais, em suas resoluções.

Pela análise da legislação que regulamenta a Odontologia no Brasil, a Constituição Federal, lei máxima do país, garante o direito de liberdade de "trabalho, ofício ou profissão," desde que "atendidas as qualificações profissionais que a lei estabelecer". A Lei Federal $n^{\circ}$ 5081/1966, que regulamenta a odontologia como profissão autônoma, permite "empregar a analgesia e a hipnose, desde que comprovadamente habilitado, quando constituírem meios eficazes para o tratamento [...]”. E a Resolução CFO 51/04 - especifica as normas para habilitação do CD na aplicação da analgesia relativa ou sedação consciente, com óxido nitroso.

Somente a sedação com óxido nitroso foi regulamentada pela odontologia e, para sua habitação, o cirurgião-dentista deve cumprir os quesitos que determinam a resolução CFO 51/04. No tocante à utilização das demais técnicas e medicamentos para sedação (incluindo a sedação com benzodiazepínicos por via oral ou endovenosa), não há normas que regulamentem a habilitação dos dentistas em tais procedimentos, apesar de a Lei Federal permitir o emprego de tais técnicas. A odontologia tem consolidado com segurança a utilização da sedação com óxido nitroso, e num futuro próximo a regulamentação de outras modalidades de sedação também deve ocorrer.

Nos Estados Unidos, existe baixa satisfação dos recém-formados sobre a qualidade da educação em sedação nas Faculdades de Odontologia. O consenso 


\section{ANÁLISE HISTÓRICO-NORMATIVA E PERSPECTIVAS FUTURAS}

geral da maioria dos graduados é que eles tiveram pouca ou nenhuma experiência prática em técnicas de sedação e que haveria um aumento do número de matrículas nas instituições que oferecessem um treinamento de sedação mais eficiente. Com maior popularidade e alta demanda de pacientes para técnicas de sedação, o novo dentista sente necessidade de educação em sedação antes de se formar (BOYNES, 2006). No Brasil, são os cursos de graduação em Odontologia, para formação do cirurgião-dentista generalista, tradicionalmente mantém a matéria de controle da dor do paciente, com enfoque na anestesia loco-regional.

Somente a anestesia loco-regional, com injeção de anestésico local intrabucal, infelizmente, não é suficiente e nem eficaz para propiciar conforto e minimizar o sofrimento para uma parcela significativa de pacientes, com por exemplo: pacientes com fobia ao tratamento dentário, crianças não-cooperativas, pacientes com necessidades especiais e pacientes que necessitam de protocolo de redução de ansiedade. O futuro da odontologia será marcado por grandes avanços enraizados em uma variedade de disciplinas, como biologia molecular, bioengenharia e ciência comportamental. Entretanto, para que os pacientes possam se beneficiar dos tratamentos que a odontologia moderna oferece, eles primeiramente devem ter acesso ao tratamento odontológico, e, dentre as barreiras que impedem a prevenção individual, estão o medo e a incapacidade de cooperação com o dentista. Nesse contexto, a sedação nos consultórios odontológicos propicia uma importante estratégia para superar essas barreiras (YAGELA, 2001).

Há currículos em que a anestesia é ensinada pelas Disciplinas de Cirurgia e em outros currículos tornou-se disciplina independente. Entretanto, há liberdade para as Faculdades organizarem o conteúdo didático-pedagógico, e as orientações da reforma curricular Resolução CNE/CES 03/2002, que instituiu as Diretrizes Curriculares Nacionais do Curso de Graduação em Odontologia, incentiva o exercício da profissão de forma articulada ao contexto social, entendendo-a como uma forma de participação e contribuição social; e o acompanhamento e incorporação de inovações tecnológicas (informática, novos materiais, biotecnologia) no exercício da profissão. Nesse sentido, há necessidade de realização de técnicas de sedação por cirurgiões-dentistas e autorização para que se incremente o ensino da sedação nos cursos de graduação.

Jürgen Habermas, em sua obra Técnica e Ciência como ideologia, demonstra que a teoria de "racionalidade" weberiana, utilizada para designar a forma da atividade econômica capitalista, das relações do direito privado burguês e da dominação burocrática, não é apenas um processo de transformação das estruturas sociais de longo prazo, mas, ao mesmo tempo, uma "racionalização" no sentido de Freud: aquela que oculta o seu motivo verdadeiro, a manutenção objetiva de uma dominação historicamente caduca por meio da invocação de imperativos técnicos. E essa invocação só é possível porque a racionalidade da ciência e da técnica já é, de forma intrínseca, uma racionalidade manipuladora, uma racionalidade de dominação. Contra essas consequências práticas de uma consciência cientificista limitada das ciências pode opor uma crítica que combate à ilusão objetivista, pela comprovação daquilo que se esconde: a conexão entre conhecimento e interesse (HABERMAS, 1929).

Nesse sentido, é necessário que se faça primeiramente uma análise ampla da questão da sedação e da anestesia na Odontologia, como feita nesse ensaio, para elucidar e sem perder de vista a compreensão positivista das ciências, trazer a discussão, também, as nuances inconfessáveis que o mero objetivismo científico oculta nas entrelinhas do tecnicismo científico e que podem responder numa dimensão maior à questão que a realidade impõe: por que os pacientes ainda têm medo e sofrem quando submetidos ao tratamento odontológico contemporâneo?

Diante da emancipação da odontologia, no futuro, haverá necessidade de se classificarem os consultórios odontológicos, usando como critério não somente a presença ou não de aparelho de raios-X, mas também conforme as técnicas de sedação e anestesia empregadas. Os currículos dos cursos de graduação devem incorporar o uso da sedação, os consultórios deverão assimilar as mudanças estruturais exigidas para a segurança do paciente. Uma melhoria na monitoração dos pacientes sedados, bem como nos equipamentos e no treinamento para o manejo de possíveis complicações, além de critérios de seleção dos pacientes e de alta pós-sedação, devem estar atualizados na prática da Odontologia Pós-moderna.

O Conselho Federal de Odontologia tem papel normativo fundamental na regulamentação das práticas 
de sedação utilizadas na odontologia. Até o momento, somente as técnicas de sedação com óxido nitroso foram regulamentadas. Outras técnicas de sedação, a exemplo do uso de benzodiazepínicos, devem ser primeiramente normatizadas pelo Conselho de Odontologia no Brasil.

Demais pesquisas devem ser realizadas no Brasil para esclarecer a questão da sedação e desenvolver linha de pesquisa no tema, para isso, inicialmente, sugerem-se trabalhos para: revisões de literatura sobre o tema sedação em odontologia; determinação de critérios de segurança para realização de sedação em consultórios odontológicos; determinar a condição atual do medo, ansiedade e dor, experimentadas pelos pacientes durante o tratamento odontológico sob anestesia local; estimar o número dos cirurgiõesdentistas que tiveram histórias de complicações com a utilização somente de anestésicos locais; determinar a formação do cirurgião-dentista brasileiro quanto aos procedimentos para controle de dor e sofrimento durante o tratamento odontológico; determinar o número de pacientes que desistem ou não acessam os serviços odontológicos por medo do dentista; determinar o número de cirurgiões-dentistas que utilizam sedação no consultório odontológico e o número de pacientes beneficiados com essa técnica.

\section{CONCLUSÃO}

O problema do controle da dor e do sofrimento durante o tratamento dentário é histórico e universal. As revoluções cognitivas, industrial e científica pelas quais passaram a humanidade permitiram o desenvolvimento de técnicas para o controle da dor e do sofrimento durante os tratamentos odontológicos. O homem não está mais sujeito à lei natural da dor e do sofrimento, causada pelas doenças ou tratamentos cirúrgicos, e tem nas técnicas de anestesia e sedação o alívio e o manejo das dores e sofrimento. Tais técnicas sempre foram objeto de disputas profissionais e refletem a dominação ou a resistência dos diversos grupos profissionais pela manutenção do status quo da profissão. Desde sua origem, a odontologia se emancipou como profissão independente, com desenvolvimento técnico-científico próprios e autonomia normativa. Apesar de toda essa evolução da analgesia e sedação, ainda hoje há muitos pacientes e um parcela da sociedade que não se beneficiam do manejo seguro e eficiente da dor e do sofrimento durante o tratamento dental, portanto, é necessário prepararmos o futuro da odontologia e os cirurgiões-dentistas para a utilização das diversas técnicas de sedação dos pacientes.

\section{REFERENCIAS}

BENSEÑOR, F.E.M.; CICARELLI, D.D. Sedação e Analgesia em Terapia Intensiva. Rev Bras Anestesiol, v. 53, n. 5, p. 680-693, 2003.

BOURKE, Joanna. The Story of Pain: from Prayer to painkillers. Oxford: Oxford University Press, 2014. 416p.

BOYNES, Sean G.; LEMAK, Anne L.; CLOSE, JOHN M. General Dentists' Evaluation of Anestesia sedation Education in U. S. Dental Schools. Journal of Dental Education, Dec. 1289-1293, 2006.

BRASIL. Constituição da República Federativa do Brasil de 1988. Disponível em: <http://www.planalto.gov.br/ ccivil_03/constituicao/constituicao.htm>. Acesso em: 24 jul. 2017.

BRASIL. Lei n ${ }^{\circ} 5081$, de 24 de agosto de 1966. Regula o Exercício da Odontologia. Disponível em: $<$ http://www. planalto.gov.br/ccivil_03/leis/15081.htm> Acesso em: 25 jul. 2017.

BRASIL. Decreto n ${ }^{\circ} 20.931$ de 11 de janeiro de 1932. Regula e fiscaliza o exercício da medicina, da odontologia, da medicina veterinária e das profissões de farmacêutico, parteira e enfermeira, no Brasil, e estabelece penas. Disponível em: <http://www.planalto.gov.br/ccivil_03/ decreto/1930-1949/D20931.htm> Acesso em: 25 jul. 2017.

BRASIL. Lein ${ }^{\circ} 1314$, de 17 de janeiro de 1951. Regulamenta o exercício dos Cirurgiões-Dentistas. Disponível em: $<$ http://www.planalto.gov.br/ccivil_03/leis/1950-1969/ L1314.htm> Acesso em: 24 jul. 2017.

CALATAYUD, J.; GONZÁLEZ, A. History of the development and evolution of local anesthesia since the coca leaf. Anesthesiology, v.98, p.1503-8, 2003.

CARVALHO, C. L. A transformação no mercado de serviços odontológicos e as disputas pelo monopólio da prática odontológica no século XIX. Hist. cienc. saude-Manguinhos, Rio de Janeiro, v. 13, n. 1, p. 55-76, mar. 2006. Disponível em: <http://www. scielo.br/scielo.php?script=sci_arttext\&pid=S0104$59702006000100004 \& \operatorname{lng}=$ en\&nrm $=$ iso $>$. Acesso em: 17 jul. 2017.

CONSELHO Federal de Odontologia. Resolução CFO $\mathbf{n}^{\circ}$ 51, de 30 de abril de 2004. Baixa normas para habilitação do CD na aplicação da analgesia relativa ou sedação consciente, com óxido nitroso. Disponível em: $<\mathrm{http}$ ://cfo. org.br/todas-as-noticias/noticias/batido-o-martelo/> Acesso em: 24 jul. 2017. 
ANÁLISE HISTÓRICO-NORMATIVA E PERSPECTIVAS FUTURAS

CONSELHO Nacional de Educação. Câmara de Educação Superior. Resolução CNE/CES 3, de 19 de fevereiro de 2002. Institui Diretrizes Curriculares Nacionais do Curso de Graduação em Odontologia. Disponível em: $<$ http://portal.mec.gov.br/cne/arquivos/pdf/CES032002. pdf> Acesso em: 23 jul. 2017.

DIONNE, Raymond A.; GORDON, Sharon M.; MCCULLAGH, Linda M.; PHERO, James C. Assessing the need for anesthesia and sedation in the general population. JADA, v. 12, p.167- 173, fev. 1998.

FACCO, Enrico; ZANETTE, Gostone. The Odyssey of Dental Anxiety: from Prehistory to the Present. A narrative review. Front. Psychol., v.8, n.1155, jul. 2017.

FÁVERO, Maria de Lourdes de Albuquerque. A Universidade no Brasil: das origens à Reforma Universitária de 1968. Educar, Curitiba, n. 28, p. 17-36, 2006. Disponível em: <http://www.scielo.br/pdf/er/n28/a03n28.pdf> Acesso em: 19 jul. 2017.

FERRARI, Mario; ALMEIDA, Fernanda Campos Souza; CAYETANO, Maristela; ARAUJO, Maria Ercilia; CALVIELI, Ida. Considerações sobre os cursos de habilitação em sedação consciente. Journal of Biodentistry and Biomaterials, São Paulo, v.2, p. 31-40, set.2011/ fev.2012.

FIGUEIREDO, Betânia Gonçalves. Barbeiros e cirurgiões: atuação dos práticos ao longo do século XIX. Hist. cienc. saude-Manguinhos, Rio de Janeiro, v. 6, n. 2, p. 277-291, Oct. 1999. Disponível em: <http://www. scielo.br/scielo.php?script=sci_arttext\&pid=S0104$59701999000300003 \& \operatorname{lng}=$ en\&nrm $=$ iso $>$. Acesso em: 17 jul. 2017.

GUSMÃO, Sebastião Silva. Pavie: um dos pioneiros da moderna medicina de Minas Gerais. Revista Eletrônica de História do Brasil, Juiz de Fora: UFJF, v. 5, n. 1, p. 48-54, set. 2002.

HABERMAS, Jürgen, 1929. Técnica e ciência como "ideologia". Tradução Felipe Gonçalves da Silva. 1. ed. São Paulo: Editora Unesp, 2014.

LINO, Patrícia Azevedo; MARTINS, Maria Auxiliadora Parreiras; SILVA, Maria Elisa de Souza Guimarães, MARO Henrique Nogueira. Anxiolytics, Sedatives, and Hypnotis prescribed by dentists in Brazil in 2 Biomed Res Int., v. 2017;2017:2841549. doi: 10.1155/2017/2841549. Epub 2017 May 30010. BioMed Research International. Disponível em: <https://www.ncbi.nlm.nih.gov/pmc/ articles/PMC5468587/pdf/BMRI2017-2841549.pdf >

LÓPEZ-VALVERDE, A.; DE VICENTE, J.; CUTANDO, A. The surgeons Halsted and Hall, cocaine and the discovery of dental anaesthesia by nerve blocking. Br Dental Journal, v.211, p. 485-487, nov.2011.
LYCH, C.D.; O'SULLIVAN, V.R.; MCGILLYCUDDY, C.T. Pierre Fauchard: the "Father of modern dentistry" Br Dent J. v.201, n.12, p.779-81, dec. 2006. Disponível em: $\quad<$ https://www.nature.com/bdj/journal/v201/n12/ full/4814350a.html>. Acesso em: 17 jul. 2017.

LYNCH, C.D.; MACGILLYCUDDY, C.T.; O'SULLIVAN, V.R. Pierre Fauchard and his role in the development of obturators. Br Dent J., v.199, n.9, p.603-5, nov. 2005. Disponível em: <https://www.nature.com/bdj/journal/v199/ n9/full/4812926a.html>. Acesso em: 17 jul. 2017.

MALAMED, Stanley F. Conscious sedation and general anesthesia techniques and drugs used in dentistry. Anesthesia Progress, v.33, n.4, p.176-178, jul./ago. 1986.

MARTINS, Wilson Denis. Pierre Fauchard, The "Father of Modern Dentistry". Rev. de Clín. Pesq. Odontol., v.2, n.1, p 71-72, ju./set. 2005. Disponível em: <http://www2.pucpr. br/reol/index.php/aor?dd99=pdf\&dd1=37>. Acesso em:17 jul. 2017.

ORR II DL. The development of anesthesiology in oral and maxillofacial surgery. Oral Maxillofacial Surg Clin N Am, v.25, p. 341-355, 2013.

PARANÁ. Secretaria de Estado da Saúde do Paraná. Resolução SESA no 496/2005. Regulamenta a Norma Técnica que estabelece condições para instalação e funcionamento de Estabelecimentos de Assistência Odontológica, e dá providências correlatas. Disponível em: <http://www.saude.pr.gov.br/arquivos/File/Legislacao/ estudual_resolucao/Res0496_05.pdf $>$ Acesso em: 24 jul. 2017.

PEREIRA, Wander. Uma história da Odontologia no Brasil. História e Perspectivas, Uberlândia, v.47, p.147-173, jul./dez. 2012. Disponível em: <http://www.seer.ufu.br/ index.php/historiaperspectivas/article/view/21268/11525> Acesso em: 17 jul. 2017.

ROUSSEAU C. Fixed and removable protheses according to Pierre Fauchard. J Hist Dent., v.48, n.2, p.79-84, jul. 2000.

SILVA, Manoel Cicero Peregrino da. Annaes da Bibliotheca Nacional do Rio de Janeiro. 1916. v.38 XXXVIII. Officinas Graphicas da Bibliotheca Nacional, 1920. Disponível em: $<<\mathrm{http}: / /$ docvirt.com/docreader.net/ DocReader.aspx?bib=anais_bn\&pagfis $=20938>$. Acesso em: 17 jul. 2017.

SOUZA Fatima Aparecida Emm Faleiros. Dor: o quinto sinal vital. Rev Latino-am Enfermagem, v.10, n.3, p.446-7, maio/ jun. 2002. Disponível em: <http://www.scielo.br/scielo. php?script $=$ sci_arttext\&pid $=$ S0104-11692002000300020> Acesso em: 2 ago. 2017.

WARMLING, Cristiane Maria; MARZOLA, Norma Regina; BOTAZZO, Carlos. Da autonomia da boca: práticas curriculares e identidade profissional na emergência do 
ensino brasileiro da Odontologia. História, Ciências, Saúde - Manguinhos, Rio de Janeiro, v. 19, n.1, p.181195, jan.-mar. 2012, Disponível em <http://www.scielo.br/ pdf/hcsm/v19n1/10.pdf> Acesso em: 18 jul. 2017.

YAGELA, John A. Making Patients safe and comfortable for a lifetime of dentistry: frontiers in office-based sedation. Journal of Dental Education, v. 65, n. 12, p. 1348-1356, 2001. 